\title{
Association of COL1A1 rs180012 SNP and Fibromyalgia Suggests the Implication of Collagen Structure in Musculoskeletal Pain
}

\author{
Isabel Navarro-Vera',2, José Antonio Casajús ${ }^{3}$, Manuel J. López-Pérezi,4*, Carmen Díez-Sánchez ${ }^{1}$ \\ ${ }^{1}$ Departamento de Bioquímica, Biología Molecular y Celular, Universidad de Zaragoza, Zaragoza, Spain \\ ${ }^{2}$ Departamento de Genética Molecular, Citogen, Zaragoza, Spain \\ ${ }^{3}$ Departmento de Fisiatría y Enfermería, Facultad de Ciencias de la Salud y el Deporte, Universidad de Zaragoza. Zaragoza, Spain \\ ${ }^{4}$ Departamento de Bioquímica, Biología Molecular y Celular-Centro de Investigaciones Biomédicas en Red de Enfermedades \\ Raras (CIBERER) - Instituto de Investigación Sanitaria de Aragón (IISA), Zaragoza, Spain \\ Email: *lopezper@unizar.es
}

How to cite this paper: Navarro-Vera, I., Casajús, J.A., López-Pérez, M.J. and Díez-Sánchez, C. (2018) Association of COL1A1 rs180012 SNP and Fibromyalgia Suggests the Implication of Collagen Structure in Musculoskeletal Pain. $A d$ vances in Bioscience and Biotechnology, 9, 83-89.

https://doi.org/10.4236/abb.2018.92007

Received: December 28, 2017

Accepted: February 20, 2018

Published: February 23, 2018

Copyright (c) 2018 by authors and Scientific Research Publishing Inc. This work is licensed under the Creative Commons Attribution-NonCommercial International License (CC BY-NC 4.0).

http://creativecommons.org/licenses/by-nc/4.0/ (c) (7) \& Open Access

\begin{abstract}
Fibromyalgia (FM) is a complex, chronic condition, which causes widespread musculoskeletal pain, fatigue and a variety of other symptoms. Many polymorphisms related to neuroendocrine system function as the ApoE isoforms, Val158Met polymorphism in COMT, as well as a 44 bp deletion located in 5-HTTLPR, have been studied. Other polymorphisms have been related to inflammatory response such as the $70 \mathrm{bp} \mathrm{VNTR} \mathrm{in} \mathrm{IL-4} \mathrm{or} \mathrm{to} \mathrm{citokine} \mathrm{levels.}$ Furthermore, some studies focused on finding out new FM related SNPs, have been performed by genome wide association scan (GWAS). The target of this work was to study a possible linkage of a collagen type I polymorphism (COL1A1 rs180012 SNP) affecting bone mineralization, with fibromyalgia. Results obtained show a clear association of $s s$ homozygous genotype with FM patients no dependent on bone mineralization.
\end{abstract}

\section{Keywords}

Fibromyalgia, Genotype, Collagen, Bone Mineral Density, SP1

\section{Introduction}

Fibromyalgia (FM) is a complex, chronic condition, which causes widespread musculoskeletal pain, fatigue and a variety of other symptoms such as sleep disturbance, headache and variable degrees of anxiety and depression [1]. It is a very heterogeneous disease, which probably affects different systems. Patients with FM have a reduced pain threshold and impaired mobility leading to the in- 
ability to fulfill an ordinary way of life.

The main symptom in FM is musculoskeletal pain, suggesting a possible but unknown impairment or general collagen defect. In this sense, some studies about the collagen metabolism and structure in patients with FM have been carried out, showing structural alterations in skin [2] and lower concentration of collagen metabolism markers in muscle or urine [3] [4]. As a whole, all these findings point to a possible common genetic origin.

In agreement with that, a polymorphism affecting the sp1 transcription factor binding site in the type I collagen $\alpha 1$ chain gene, (rs180012 in COL1A1) has been studied. It has been shown that one of the COL1A1 genotypes (ss) leads to a wrong packaging of the protein affecting bone mineralization [5]. This polymorphism has been associated with bone mineral density (BMD) [6], osteoporosis [7] and fragility fractures.

Functional analysis has shown that s allele (g.2046G > T) of the Sp1-COL1A1 binding site polymorphism is associated with a higher rate of DNA-protein binding, leading to transcription increase, and enhancing levels of COL1A1 protein [8]. This over-production leads to an imbalance between type I collagen $\alpha 1$ and $\alpha 2$ chains resulting in impaired bone strength and mass.

Taking all together, the aim of this study was to find out if the rs 180012 polymorphism was associated to FM. In addition, a whole body Dual X-ray Absorciomoetry (DXA) test, which is considered the gold standard method to establish body composition parameters, was performed on a representative group of participants, in order to find out a potential association between this polymorphism and BMD values in FM.

\section{Materials and Methods}

Ethical clearance: The Research Ethics Committee of the Aragon Government (CEICA, Spain) accepted the protocol and each subject signed an informed consent according to the declaration of Helsinki before entering the study. Life style information was collected through personal interviews using structured questionnaires and followed by physical examination.

Patients group. Two hundred and thirteen women from the Association of Fibromyalgia and Chronic Fatigue Syndrome of Aragon (ASAFA) were recruited for our study. All of them had been diagnosed of FM, according to the ACR criteria, at least five years before the start of the study.

Control group. To compare with the patient group, one hundred and thirty six age-matched women were selected. None of them have reported pain episodes in the previous six months or was diagnosed from any pain related disease.

Genotyping. Peripheral blood samples were collected in $5 \mathrm{~mL}$ EDTA Vacutainer tubes. DNA was obtained following the standard procedure with some modifications. COL1A1 rs180012 SNP was genotyped by PCR and subsequent Sanger sequencing analysis. Primers used for the amplification were F-5'-TAACTTCTGGACTATTTGCGGACTTTTTGG-3' and R-5'-GTCCAG 
CCCTCATCCTGGCC-3’ and Tm was $62^{\circ} \mathrm{C}$. Capillary sequencing was performed 96 well plates including water blanks and DNA samples with known genotypes to monitor quality control in a 3100 Avant sequencer (Applied Biosystems) following the manufacturer protocol.

Body composition measurements. A subgroup consisting of 27 patients and 24 controls was selected randomly to perform the body composition assessment. A dual-X-ray absorptiometry (DXA) scanner (QDR-Explorer, Hologic Corp., Software version 12.4, Waltham, MA, USA) was used to evaluate whole-body bone mineral content, BMC $(\mathrm{g})$, and bone mineral density, BMD $\left(\mathrm{g} / \mathrm{cm}^{2}\right)$ as previously described [9]. All DXA scans were performed with the same software and device, which was regularly calibrated by the same technician who had been fully trained in the position of the participants, operation of the scanner and analysis of results, according to manufacturer guidelines.

Statistical analysis. Data are presented as mean \pm SD. In case of quantitative variants, Kolmogorov-Smirnoff test was applied to test normality of the distribution, followed by Mann-Whitney U test, or Unpaired T-test. Significant differences were assumed when $\mathrm{P} \leq 0.05$. The genotypic distribution in controls and patients was calculated by contingency table analyses.

All statistical analysis were carried out with the statistical packages Stat View 5.0 ( ) 1992-98 SAS Institute Inc.

\section{Results}

All subjects, controls (age $52.5 \pm 7.8$ ) and patients (age $52.5 \pm 7.8$ ), were asked to fulfill a nutritional, medical, life habits and familial history questionnaire. No significant differences were found among the collected characterization data. Interestingly there was no significant differences in the amount of directed physical activity. In this sense and as expected all the patients were recruited from ASAFA, (association of FM patients) which promotes and organizes physical activities for its members.

Some basic anthropometric parameters were measured in both groups. The values were uniform and similar between populations, however significant differences were observed in weight and subsequently in body mass index (BMI), with patients presenting overweight, since BMI is over 25 (Table 1).

Regarding the genetic study of the SP1 binding site polymorphism in COL1A1, we found a very strong correlation between the ss genotype and the patient group. Contingency table showed a strong correlation between the ss genotype and the FM group $\left(\chi^{2}=27.57\right.$ with $1 \mathrm{DF}$ and $\left.\mathrm{P}<0.0001\right)$ showing an accumulation of the ss genotype. When the contribution of the polymorphism genotypes to $\chi^{2}$ was examined, it could be appreciated that COL1A1 ss ( $\chi^{2}$ contribution 13,521) was responsible for the high $\chi^{2}$ Furthermore, a post hoc analysis on the cell contribution to $\chi^{2}$ revealed that a significant deviation from the expected frequencies could be observed for the enhanced presence of COL1A1 ss allele in the patient group. On behave of these results, the allele frequencies of 
rs18002 were determined, showing a strong difference between control $(\mathrm{S}, \mathrm{p}=$ $0.79 ; \mathrm{s}, \mathrm{q}=0.21$ ) and patient $(\mathrm{S}, \mathrm{p}=0.64 ; \mathrm{s}, \mathrm{q}=0.36$ ) population (Figure 1 ).

Finally, as shown in Figure 2, no differences could be observed in the BMD

Table 1. Major anthropometrical parameters in control and FM groups. Numbers correspond to mean values \pm standard deviations. P corresponds to Fischer's PLSD post-hoc test. Perim: perimeter.

\begin{tabular}{cccc}
\hline & Control & Patient & P \\
\cline { 1 - 2 } & Mean \pm SD & Mean \pm SD & \\
\hline Hip per. $(\mathrm{cm})^{*}$ & $97.92 \pm 8.8$ & $103.2 \pm 12.1$ & 0.16 \\
Waist per.$(\mathrm{cm})^{*}$ & $76.6 \pm 9.8$ & $83.42 \pm 13.9$ & 0.12 \\
Weight $(\mathrm{Kg})^{*}$ & $61.08 \pm 8.5$ & $70.77 \pm 14.9$ & 0.004 \\
Height $(\mathrm{cm})^{\dagger}$ & $160.57 \pm 6.3$ & $157.9 \pm 6.2$ & 0.13 \\
BMI $\left(\mathrm{Kg} /(\mathrm{m})^{2}\right)^{\dagger}$ & $23.7 \pm 3.08$ & $28.4 \pm 6.24$ & 0.0005 \\
\hline
\end{tabular}

'Per: Perimeter; ${ }^{*}$ Mann-Whitney U test, K-S P $<0.05$; ${ }^{\dagger}$ Unpaired T-test, K-S P $>0.05$.

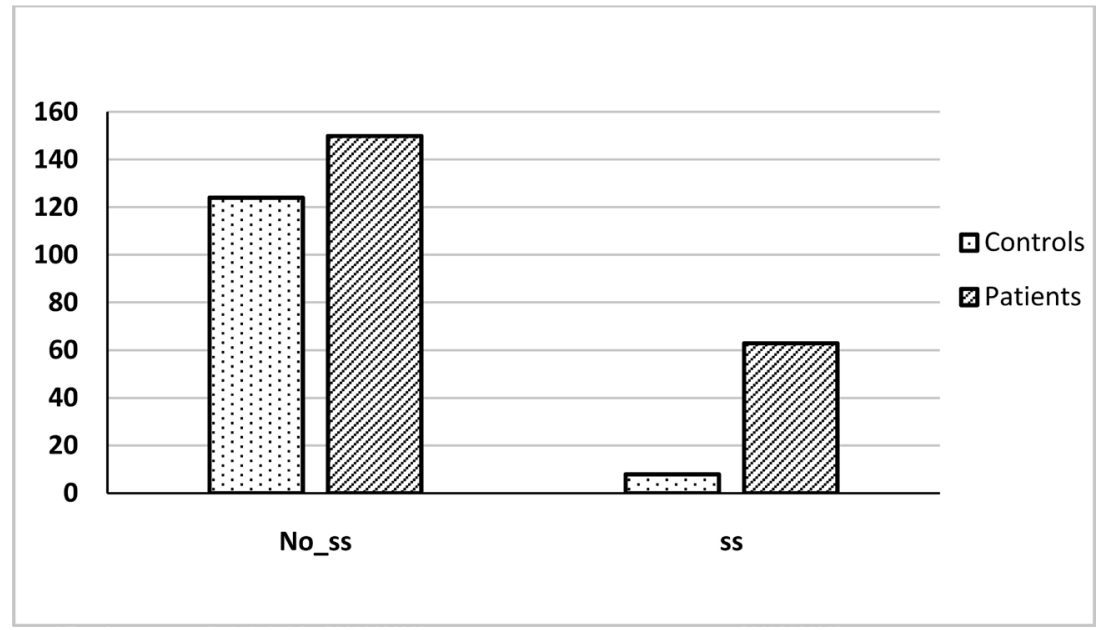

Figure 1. Genotype distribution in patient and control population. No_ss: summatory of SS and Ss genotypes. Y axys shows individual number.

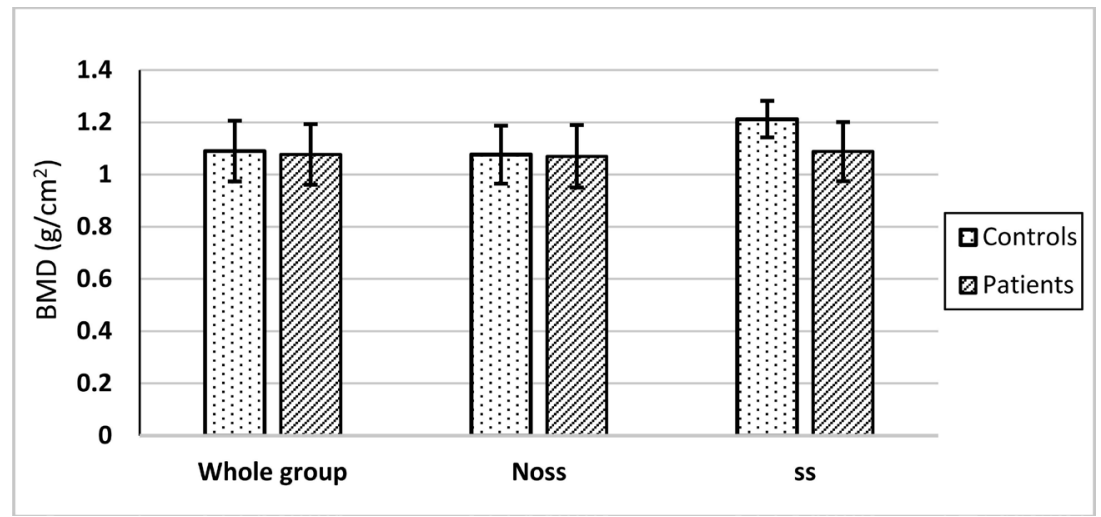

Figure 2. Correlation between BMD values and genotype. Comparison between bone mineral density values in control and patient population, taking the whole two populations together and splitting them by genotype. 
values between control and patient group. Moreover, no differences were observed when splitting these populations by the rs180012 genotypes.

\section{Discussion}

FM is a common disorder in which musculoskeletal pain, stiffness and muscle fatigue appear as the main symptoms. Different studies have reported controversial results about possible defective muscle fibres [10] [11] [12]. In this study we focused on a possible genetic background, looking for a correlation between FM and a SNP (rs180012) which has been previously associated with abnormal structure of the COL1A1 molecule which plays a very important role in skeletal muscle structures [5] [8]. In addition, DXA analysis was carried out to find the potential correlation between FM and abnormal BMD values in patients.

Several authors studying osteoporosis and post-menopausal women have reported correlations between the rs180012 genotypes and BMD values. These studies showed association with bone density, fragility fractures [13] and bone mineralization [5]. Recent studies showed correlation of this COL1A1 polymorphism to BMD in spine and femur [14].

In the current study, a strong association $(\mathrm{p}<0.0001)$ between the s allele in the COL1A1 polymorphism studied and FM presence was found. The rs 18002 SNP has been associated by several authors to an increase of the gene transcription and the subsequent increase in the corresponding protein rates. Subsequently, the imbalance produced between the collagen type $1 \alpha 1$ and $\alpha 2$ chains would lead to a reduced bone mass and a deficiency in the bone strength in allele s carriers, what would affect their bone mineralization. Moreover, retrospective meta analysis showed that the carriage of the $s$ allele is associated with low BMD [15], homozygotes for this allele were found to be associated to low BMD and vertebral fractures in a large study with over 20.000 participants of the Genetic Markers for Osteoporosis (GENOMOS) study [16].

Our study indicates no correlation between the genotype of the polymorphism in the first intron of the COL1A1 gene and the BMD values measured by DXA in the studied population, neither taking the whole population together, nor splitting it into controls and patients. However, a strong correlation was found when analyzing data referring to the rs180012 genotype. In the FM patient group, the ss genotype was highly represented, whereas no genotype showed correlation with the controls.

Previous studies have shown a diminished collagen type 1 metabolite rate in urine and a wrong packaging for this protein in skin samples when FM patients were studied [2]. Furthermore, Gronemann et al. showed a lower collagen concentration in muscle of FM patients vs control group [3], which would explain weakness of the supportive connective tissue and a reduced increase of muscle collagen in response to exercise. This situation would increase the number of micro-injuries in FM patients, since their lower collagen concentration in muscle would reduce their capability to restore these micro-injuries. 
The current study supports the above mentioned hypothesis as a strong correlation between FM and the ss genotype has been found, appearing as a possible mechanism determining a lower content of functional collagen in muscle. Very interestingly, $\mathrm{sp} 1$ is a widely present transcriptional factor with very specific and variable tissue, functional, epigenetic and multifactorial agents [17]. This points to the possibility of a tissue specific action of the SNP variants effects, changing specifically in different tissues and diseases. In any case, our findings open the question of rs180012 SNP as a possible genetic risk factor for developing FM or other musculoskeletal pain syndromes.

\section{Acknowledgements}

The authors want to thank all the patients and women in the control group for their participation in the study. The OTRI, Universidad de Zaragoza. Departamento de Ciencia, Tecnología y Universidad del Gobierno de Aragón (Grupos Consolidados B33) and FEDER Funding Program from the European Union. The CIBERER is an initiative of the ISCIII, and also ASAFA for supporting it and the staff from the HELENA project for their help with the DXA analyses.

\section{References}

[1] Wolfe, F., Smythe, H.A., Yunus, M.B., Bennett, R.M., Bombardier, C., Goldenberg, D.L., Tugwell, P., Campbell, S.M., Abeles, M. and Clark, P. (1990) The American College of Rheumatology 1990 Criteria for the Classification of Fibromyalgia. Report of the Multicenter Criteria Committee. Arthritis \& Rheumatology, 33, 160-172. https://doi.org/10.1002/art.1780330203

[2] Ribel-Madsen, S., Gronemann, S.T., Bartels, E.M., Danneskiold-Samsøe, B. and Bliddal, H. (2005) Collagen Structure in Skin from Fibromyalgia Patients. International Journal of Tissue Reactions, 27, 75-82.

[3] Gronemann, S.T., Ribel-Madsen, S., Bartels, E.M., Danneskiold-Samsoe, B. and Bliddal, H. (2004) Collagen and Muscle Pathology in Fibromyalgia Patients. Rheumatology (Oxford), 43, 27-31. https://doi.org/10.1093/rheumatology/keg452

[4] Ribel-Madsen, S., Christgau, S., Gronemann, S.T., Bartels, E.M., Danneskiold-Samsøe, B. and Bliddal, H. (2007) Urinary Markers of Altered Collagen Metabolism in Fibromyalgia Patients. Scandinavian Journal of Rheumatology, 36, 470-477. https://doi.org/10.1080/03009740701483048

[5] Stewart, T.L., Roschger, P., Misof, B.M., Mann, V., Fratzl, P., Klaushofer, K., Aspden, R. and Ralston, S.H. (2005) Association of COLIA1 Sp1 Alleles with Defective Bone Nodule Formation in Vitro and Abnormal Bone Mineralization in Vivo. Calcified Tissue International, 77, 113-118. https://doi.org/10.1007/s00223-004-0188-8

[6] Grant, S.F., Reid, D.M., Blake, G., Herd, R., Fogelman, I. and Ralston, S.H. (1996) Reduced Bone Density and Osteoporosis Associated with a Polymorphic Sp1 Binding Site in the Collagen Type I Alpha 1 Gene. Nature Genetics, 14, 203-205. https://doi.org/10.1038/ng1096-203

[7] MacDonald, H.M., McGuigan, F.A., New, S.A., Campbell, M.K., Golden, M.H., Ralston, S.H. and Reid, D.M. (2001) COL1A1 Sp1 Polymorphism Predicts Perimenopausal and Early Postmenopausal Spinal Bone Loss. Journal of Bone and Mineral 
Research, 16, 1634-1641. https://doi.org/10.1359/jbmr.2001.16.9.1634

[8] Mann, V., Hobson, E.E., Li, B., Stewart, T.L., Grant, S.F., Robins, S.P., Aspden, R.M. and Ralston, S.H. (2001) A COL1A1 Sp1 Binding Site Polymorphism Predisposes to Osteoporotic Fracture by Affecting Bone Density and Quality. Journal of Clinical Investigation, 107, 899-907. https://doi.org/10.1172/JCI10347

[9] Vicente-Rodriguez, G., Ara, I., Perez-Gomez, J., Dorado, C. and Calbet, J.A. (2005) Muscular Development and Physical Activity as Major Determinants of Femoral Bone Mass Acquisition during Growth. British Journal of Sports Medicine, 39, 611-616. https://doi.org/10.1136/bjsm.2004.014431

[10] Kalyan-Raman, U.P., Kalyan-Raman, K., Yunus, M.B. and Masi, A.T. (1984) Muscle Pathology in Primary Fibromyalgia Syndrome: A Light Microscopic, Histochemical and Ultrastructural Study. The Journal of Rheumatology, 11, 808-813.

[11] Elert, J.E., Rantapää-Dahlqvist, S.B., Henriksson-Larsén, K., Lorentzon, R. and Gerdlé, B.U. (1992) Muscle Performance, Electromyography and Fibre Type Composition in Fibromyalgia and Work-Related Myalgia. Scandinavian Journal of Rheumatology, 21, 28-34. https://doi.org/10.3109/03009749209095059

[12] Drewes, A.M., Andreasen, A., Schrøder, H.D., Høgsaa, B. and Jennum, P. (1993) Pathology of Skeletal Muscle in Fibromyalgia: A Histo-Immuno-Chemical and U1trastructural Study. British Journal of Rheumatology, 32, 479-483. https://doi.org/10.1093/rheumatology/32.6.479

[13] Uitterlinden, A.G., Burger, H., Huang, Q., Yue, F., McGuigan, F.E., Grant, S.F., Hofman, A., van Leeuwen, J.P., Pols, H.A. and Ralston, S.H.(1998) Relation of Alleles of the Collagen Type Ialphal Gene to Bone Density and the Risk of Osteoporotic Fractures in Postmenopausal Women. The New England Journal of Medicine, 338, 1016-1021. https://doi.org/10.1056/NEJM199804093381502

[14] Mann, V. and Ralston, S.H. (2003) Meta-Analysis of COL1A1 Sp1 Polymorphism in Relation to Bone Mineral Density and Osteoporotic Fracture. Bone, 32, 711-717. https://doi.org/10.1016/S8756-3282(03)00087-5

[15] Efstathiadou, Z., Tsatsoulis, A. and Ioannidis, J.P. (2001) Association of Collagen Ialpha1 Sp1 Polymorphism with the Risk of Prevalent Fractures: A Meta-Analysis. Journal of Bone and Mineral Research, 16, 1586-1592. https://doi.org/10.1359/jbmr.2001.16.9.1586

[16] Ralston, S.H., Uitterlinden, A.G., Brandi, M.L., Balcells, S., Langdahl, B.L., Lips, P., Lorenc, R., Obermayer-Pietsch, B., Scollen, S., Bustamante, M., Husted, L.B., Carey, A.H., Diez-Perez, A., Dunning, A.M., Falchetti, A., Karczmarewicz, E., Kruk, M., van Leeuwen, J.P., van Meurs, J.B., Mangion, J., McGuigan, F.E., Mellibovsky, L., del Monte, F., Pols, H.A., Reeve, J., Reid, D.M., Renner, W., Rivadeneira, F., van Schoor, N.M., Sherlock, R.E. and Ioannidis, J.P. (2006) Large-Scale Evidence for the Effect of the COLIA1 Sp1 Polymorphism on Osteoporosis Outcomes: The GENOMOS Study. PLOS Medicine, 3, e90. https://doi.org/10.1371/journal.pmed.0030090

[17] O'Connor, L., Gilmour, J. and Bonifer, C. (2016) The Role of the Ubiquitously Expressed Transcription Factor Sp1 in Tissue-Specific Transcriptional Regulation and in Disease. The Yale Journal of Biology and Medicine, 89, 513-525. 